\title{
Ectrópio palpebral em portador da síndrome de Down e conjuntivite alérgica: relato de caso
}

\author{
Eyelid ectropion in Down's syndrome related to allergicconjunctivitis:case report
}

\author{
Claudia Akemi Shiratori ${ }^{1}$ \\ Maria Claudia Komatsu² \\ Silvana Artioli Schellini ${ }^{3}$ \\ Tadeu Cvintal ${ }^{4}$
}

\begin{tabular}{|c|}
\hline RESUMO \\
\hline Relata-se o caso de paciente com síndrome de Down, portador de impor- \\
tante ectrópio mecânico da pálpebra inferior, relacionado com conjuntivite \\
alérgica, catarata ceratocone. Foi feito tratamento cirúrgico, empregando \\
a técnica de "tarsal strip" e ressecção da lamela posterior que estava \\
redundante e espessa, com bom resultado estético e funcional.
\end{tabular}

Descritores: Ectrópio; Blefaroplastia; Conjuntiva/cirurgia; Conjuntivite alérgica; Síndrome de Down; Relatos de casos [Tipo de publicação]

\section{INTRODUĈ̃O}

A síndrome de Down representa uma anomalia cromossômica freqüente, relatada aproximadamente em 1 a cada 700 nascidos vivos ${ }^{(1)}$. Inúmeras são as alterações oculares que podem ocorrer nesta síndrome: catarata, ceratocone, estrabismo, manchas de Brushfield, triquíase, epífora, nistagmo e altas ametropias (principalmente miopia) ${ }^{(1-2)}$. Também alterações palpebrais são freqüentes e contribuem para o estereótipo da síndrome, como fendas palpebrais oblíquas e estreitas, epicanto, blefarite crônica, blefaroconjuntivite, eversão congênita das pálpebras superiores, ectrópio ou entrópio de pálpebras superiores e inferiores e euribléfaro ${ }^{(1-4)}$.

O objetivo deste relato é apresentar um portador da síndrome de Down que apresentou uma alteração palpebral rara: o ectrópio mecânico da pálpebra inferior, associado à conjuntivite alérgica e como foi feita a abordagem terapêutica.

(SP) - Brasil.

Oftalmologista. Instituto Tadeu Cvintal - São Paulo (SP) - Brasil.

2 Oftalmologista. Instituto Tadeu Cvintal - São Paulo (SP) - Brasil.

3 Professora Livre Docente da Faculdade de Medicina

Universidade Estadual Paulista "Júlio Mesquita Filho"

- UNESP - Botucatu (SP) - Brasil.

${ }^{4}$ Oftalmologista. Instituto Tadeu Cvintal - São Paulo (SP) - Brasil.

Endereço para correspondência: Silvana Artioli Schellini Faculdade de Medicina de Botucatu - Campus Universitário Departamento de OFT/ORL/CCP - Botucatu (SP) CEP18618-000

E-mail: sartioli@fmb.unesp.br

Recebido para publicação em 01.06.2006

Última versão recebida em 04.12.2006

Aprovação em 08.01.2007

Nota Editorial: Depois de concluída a análise do artigo sob sigilo editorial e com a anuência da Dra. Joelice dos Santos Araújo sobre a divulgação de seu nome como revisor, agradecemos sua participação neste processo.

\section{RELATO DO CASO}

EAB, masculino, 29 anos, portador de síndrome de Down, há 8 anos com ectrópio de pálpebras inferiores, com melhora na pálpebra inferior esquerda após uso de colírios para tratamento de conjuntivite alérgica e manutenção do quadro à direita.

Antecedentes pessoais: asma brônquica, cardiopatia e debilidade mental.

Antecedentes oculares: conjuntivite alérgica tratada com vários colírios (anti-histamínicos, estabilizadores de membrana de mastócitos e corticosteróides) por longo período.

Exame externo: ectrópio mecânico da pálpebra inferior direita, associado com flacidez palpebral e eversão importante da margem palpebral e exposição da conjuntiva tarsal que se encontrava ceratinizada e espessada. O mesmo aspecto de conjuntiva foi observado à eversão de pálpebra superior direita (Figura 1).

Acuidade visual: não informa, mas com boa fixação ocular.
} 
Biomicroscopia: conjuntiva tarsal superior e inferior de ambos olhos com hiperplasia e papilas gigantes, principalmente no fórnice inferior direito. Ambos olhos com afinamento corneano discreto, paracentral inferior, leucoma apical e catarata pulverulenta.

Fundoscopia indireta: apesar de dificultada, apresenta reflexo vermelho positivo nos olhos.

Tratamento cirúrgico: Encurtamento horizontal da pálpebra inferior (técnica de "tarsal strip"), associada à ressecção de retalho horizontal de lamela posterior das pálpebras. Para facilitar a ressecção da lamela posterior foi feito o clampeamento horizontal da conjuntiva espessada, usando pinça de reparo, em toda extensão evertida, ressecando-se a conjuntiva redundante e espessada e o tecido fibrótico subjacente, com cauterização dos vasos sangrantes e sutura contínua da conjuntiva com fio absorvível trançado 7-0. O material removido foi fixado em formol $10 \%$ e preparado para exame em microscópio de luz.

Resultado do exame histológico: epitélio escamoso metaplásico, revestindo córion, com intensa inflamação crônica inespecífica.

Evolução pós-operatória: fechamento palpebral efetivo, sem exposição corneana. O resultado foi considerado esteticamente satisfatório, com melhora dos sintomas (Figuras 2 e 3 ).

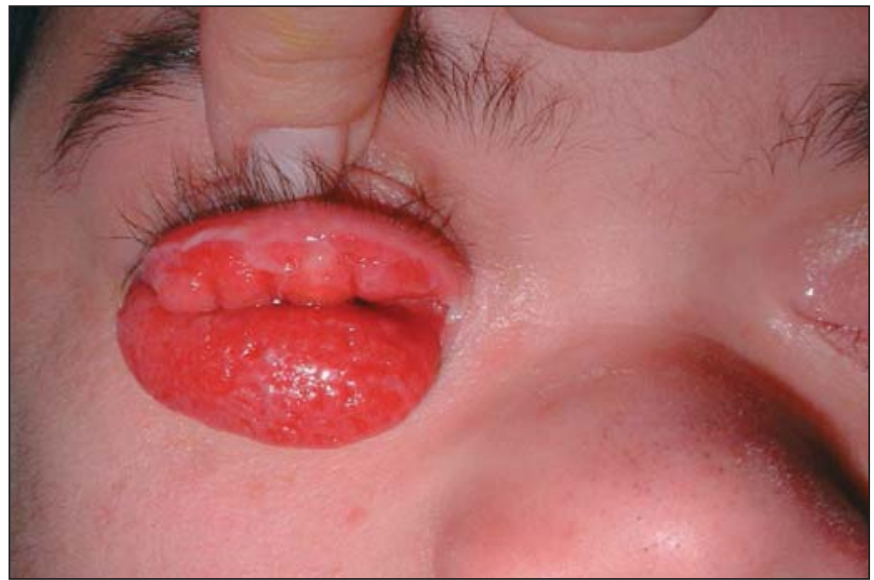

Figura 1 - Ectrópio mecânico da pálpebra inferior, com espessamento intenso da conjuntiva palpebral e flacidez de ambas as pálpebras

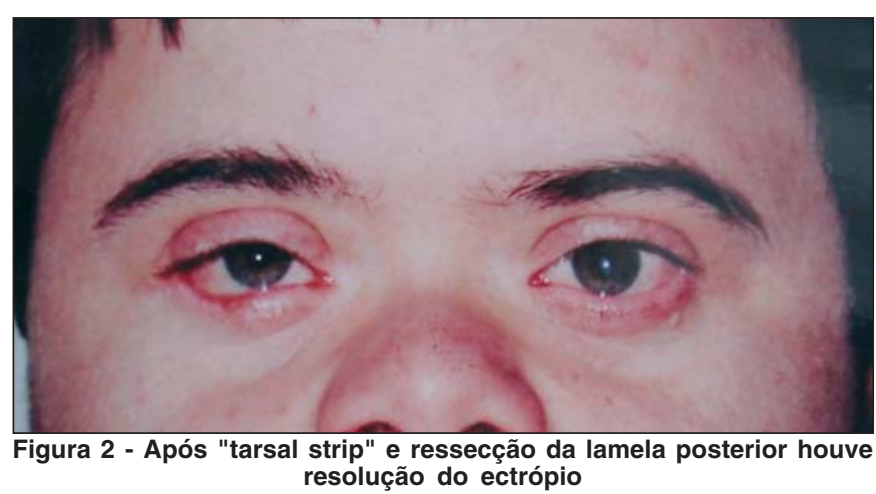

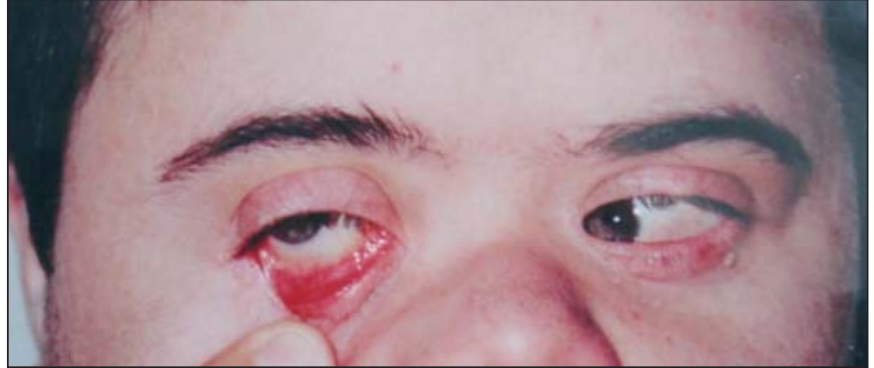

Figura 3 - Observar melhora do aspecto da conjuntiva tarsal

\section{DISCUSSÃO}

O ectrópio pode ocorrer por diversos mecanismos, podendo ser classificado em congênito, involucional, cicatricial (queimaduras químicas ou físicas, lesões actínicas da pele palpebral), mecânico (tração da pálpebra para baixo), iatrogênico.

$\mathrm{Na}$ síndrome de Down o ectrópio congênito é mais freqüente do que em outras crianças ${ }^{(5)}$, podendo estar associado à flacidez ligamentar. Entretanto, observou-se aqui uma causa mecânica provocando a eversão palpebral que pode ter se iniciado pela existência de conjuntivite alérgica. A conjuntiva tarsal exposta tornou-se espessa, facilitando e perpetuando a eversão palpebral.

Este mecanismo é freqüente nos processos alérgicos, quando a reação de hipersensibilidade do tipo 1 leva à degranulação de mastócitos, liberação de aminas vasoativas, citocinas e mediadores químicos, como o fator quimiotático eosinofílico e a proteína básica maior ${ }^{(6)}$, com vasodilatação e extravasamento de líquido para a submucosa conjuntival, ocasionando os sintomas inflamatórios que podem se tornar $\operatorname{crônicos}^{(7)}$.

O longo período de inflamação conjuntival e quemose, pode contribuir para a flacidez horizontal da pálpebra ${ }^{(1)}$, agravando a flacidez ligamentar e hipotonia da musculatura da face, presentes nos portadores de síndrome de Down.

O ceratocone pode ocorrer na síndrome de Down. Entretanto, 10 a $16 \%$ dos portadores de alergia ocular podem apresentar ceratocone, devido ao ato de coçar o olho ou pela liberação de citocinas no processo alérgico ${ }^{(6)}$. Portanto, o paciente em questão poderia ter desenvolvido o ceratocone secundariamente à conjuntivite alérgica.

A catarata muitas vezes pode ocorrer como complicação devido ao uso de corticosteróides para o tratamento da alergia ocular $^{(1)}$. Entretanto, a opacificação heterogênea do cristalino, com aspecto pulverulento, em ambos olhos, confere aspecto mais de catarata congênita.

A técnica cirúrgica empregada demandou, além do "tarsal strip", a ressecção da lamela posterior uma vez que, após 8 anos de exposição, a conjuntiva tarsal desenvolveu metaplasia, ceratinização e alterações cicatriciais, fazendo-se necessária a ressecção das áreas de fibrose para que fosse possível corrigir a deformidade palpebral.

Para esta ressecção a técnica empregada foi semelhante ao 
que se realiza na cirurgia de Fasanella-Servat para correção da ptose, sem que houvesse intenção de atuar no plano do músculo retrator da pálpebra inferior, uma vez que o tecido ressecado correspondia à conjuntiva tarsal herniada e espessada e o tecido estromal conjuntival fibrosado. Desta forma, o resultado obtido trouxe não somente benefícios estéticos, mas também funcionais, por remover o tecido que impedia o adequado deslizamento e posicionamento das pálpebras.

Finalizando, gostaríamos de frisar a raridade do relato, não havendo até o momento citações na literatura, não somente pela relação do ectrópio mecânico com a conjuntivite alérgica em portadores da síndrome de Down, como a técnica cirúrgica empregada, que foi eficiente.

\section{ABSTRACT}

This is a case report of a patient with Down's syndrome with an important mechanical ectropion and elongation of the lower lid related to chronic allergic conjunctivitis, besides cataract and keratoconus. The tarsal strip technique and ressection of redundant and thick conjunctiva was the surgical approach chosen for this case. Functional and cosmetic outcomes were considered satisfactory.

Keywords: Ectropion; Blepharoplasty; Conjunctiva/surgery; Conjunctivitis, allergic; Down syndrome; Case reports [Publication type]

\section{REFERÊNCIAS}

1. Morris RJ, Collin JRO. Functional lid surgery in Down's syndrome. Br J Ophthalmol. 1989;73(7):494-7.

2. Johnson CC, McGowan BL. Am J Ophthalmol. 1969;67(2):252-6.

3. Gilbert HD, Smith RE, Barlow MH, Mohr D. Congenital upper eyelid eversion and Down's syndrome. Am J Ophthalmol. 1973;75(3):469-72.

4. Brik D, Cenovicz MT, Cruz AO. Euribléfaro e ectrópio congênitos associados a Síndrome de Down. Arq Bras Oftalmol. 1990;53(5):219-21.

5. Sellar PW, Bryars JH, Archer DB. Late presentation of congenital ectropion of the eyelids in a child with Down syndrome: a case report and review of the literature. J Pediatr Ophthalmol Strabismus. 1992;29(1):64-7.

6. Botelho PBM, Marback P, Sousa LB, Campos M. Ceratoconjuntivite alérgica e complicações no segmento ocular anterior de pacientes. Arq Bras Oftalmol. 2003;66(1):25-8.

7. Bezerra HL, Rizzo LV, Yu MCZ, Freitas D. Avaliação da resposta terapêutica nas alergias oculares por meio de citologia exfoliativa. Arq Bras Oftalmol. 2003;66(5):595-8 